\title{
ODOVTOS
}

International Journal of Dental Sciences

https://revistas.ucr.ac.cr/index. php/Odontos I ISSN: 2215-3411

Received:

$21-\mathrm{VIII}-2020$

Accepted:

27-XI-2020

Published Online:

$14-X \mid I-2020$

\section{Pediatric Oral Vitiligo: Case Report and Literature Review}

\section{Vitiligo oral pediátrico: reporte de caso y revisión de la literatura}

Manu Sharma BDS, MDS1; Arishiya Thapasum Fairozekhan BDS, MDS²;

Faraz Mohammed BDS, MDS3; S.R. Janani BDS MDS OMFP4; R.N. Mugundan BDS MDS

OMFP5; Evangeline Cynthia Dhinakaran MBBS DMCH6; Pragadeesh Subramaniam MBBS7; Karthik Shunmugavelu BDS, MSC (LONDON), (MDS OMFP), MFDS RCSENG, MCIP, FIBMS (USA), MASID (AUSTRALIA) ${ }^{8}$

1. Senior lecturer. Paedodontics and Preventive Dentistry, Swami Devi Dyal Hospital and Dental College, Barwala, District Panchkula, Haryana, India. https://orcid.org/0000-0002-2197-1450 2. Department of Biomedical Dental Sciences, College of Dentistry, Imam Abdulrahman Bin Faisal University, Dammam, Kingdom of Saudi Arabia. https://orcid.org/0000-0002-9223-7966 3. Department of Biomedical Dental Sciences, College of Dentistry, Imam Abdulrahman Bin Faisal University, Dammam, Kingdom of Saudi Arabia. https://orcid.org/0000-0002-2440-1058 4. Consultant-Dentistry/Oral and Maxillofacial Pathology, Mercy Multispeciality Dental Centre, Tamilnadu, India. https://orcid.org/0000-0003-2993-6542

5. Consultant-Dentistry/Oral and Maxillofacial Pathology, Mercy Multispeciality Dental Centre, Tamilnadu, India. https://orcid.org/0000-0002-3459-0454

6. Fellowship US-OBG (MD Pathology). Mercy Multispeciality Dental Centre, Tamilnadu, India. https://orcid.org/0000-0003-2194-6455

7. Mercy Multispeciality Dental Centre, Tamilnadu, India. https://orcid.org/0000-0003-1887-1800

8. Director/Consultant-Dentistry/Oral and Maxillofacial Pathology. Mercy Multispeciality Dental Centre, Tamilnadu, India. https://orcid.org/0000-0001-7562-8802

Correspondence to: Dr. Karthik Shunmugavelu - drkarthiks1981@gmail.com

ABSTRACT: Vitiligo is an acquired hypomelanotic disorder of the skin resulting from loss of functional melanoctyes and it affects approximately $0.5-1 \%$ of individuals. $25 \%$ of vitiligo in children are diagnosed before 10 years of age. The age of onset of vitiligo in children ranges between 4 to 8 years. Depigmentation in oral cavity can be easily noted and awareness about the condition can be created if they are not aware about vitiligo elsewhere in their body and can be guided for the treatment.

KEYWORDS: Oral vitiligo; Depigmentation; Hypomelanotic. 
RESUMEN: El vitíligo es un trastorno hipomelanótico en la piel que resulta de la pérdida de melanocitos funcionales y afecta aproximadamente al 0,5-1\% de los individuos. El $25 \%$ de los casos de vitiligo en niños se diagnostican antes de los 10 años. La edad de aparición del vitiligo en los niños oscila entre los 4 y los 8 años. La despigmentación en la cavidad oral se puede notar fácilmente y se puede crear conciencia sobre la afección, si no son conscientes del vitiligo en otras partes de su cuerpo, y pueden ser guiados para el tratamiento.

PALABRAS CLAVE: Vitiligo oral; Despigmentación; Hipomelanótico.

\section{INTRODUCTION}

Vitiligo is a depigmenting disorder of the skin which is characterized by selective loss of melanocytes and leads to pigment dilution in affected skin areas. The vitiligo lesion is a totally amelanotic, non-scaly chalky white macule with distinct margin. Now it has been classified as an autoimmune disease, associated with genetic, environmental factors, metabolic disorders and cell detachment abnormalities (1). $50 \%$ of the patients have childhood onset of the disease and the prevalence of vitiligo is $1-2 \%$ worldwide. Female predominance is seen in pediatric vitiligo as seen in adult vitiligo. The vitiligo lesions in pediatric patients are distributed as generalized disease $-34 \%$ followed by acrofacial $-13 \%$, mucosal $-3 \%$, segmental $-29 \%$, and undetermined $-21 \%$. The psychological problems such as depression, lower self-esteem, anxiety and poor quality of life are seen in childhood vitiligo. The autoimmune diseases such as thyroiditis, pernicious anemia, atopic dermatitis, diabetes mellitus and alopecia areata are associated with vitiligo (2). $25 \%$ of vitiligo in children are diagnosed before 10 years of age. The age of onset of vitiligo in children ranges between 4 to 8 years (3). So far, vitiligo is the most frequent disorder of pigmentation. Prevalence of vitiligo in India is $8.8 \%$ which is highest in the world and in U.S.A. it is about $1 \%$. In addition, in world about $1 \%$ of the population has vitiligo according to the literature (4). In the literature only very few cases of oral vitiligo have been reported. Vitiligo of the oral mucosa is rare. Lip is most commonly affected followed by palate and gingiva. Immunomodulators, micropigmentation, phototherapy, and invasive surgical treatment are the various treatment modalities followed in treating the disease. In the oral region, the response to the treatment is very minimal and hence the early diagnosis helps in treatment success and also reduces the aesthetic damage.

\section{CASE REPORT}

A 9 year old patient reported to the department of oral pathology with the chief complaint of a whitish patch on her lips for the past two year. The lesion was asymptomatic. Initially the lesion was a small dot and gradually increased to the present size. The patient was healthy and was not taking any medication. There was no familial history of the present disease and nor a history of trauma on the affected site. The patient's parents were concerned about the color change in the child's lip and reported to the hospital to find the underlying cause.

Extra orally, there was no abnormality detected and there was no lesions elsewhere in the body. Intra orally, in vermilion border of the lip, there was a diffuse patch of size $2.5 \times 3.5 \mathrm{~cm}$ involving the labial mucosa. Laboratory examinations were ordered for complete blood count, hemoglobin, TSH, anti-thyroglobulin and anti-thyroperoxidase 
antibodies. No abnormalities were present in the results. The thyroid examination was done to rule out the autoimmune disorder associated with vitiligo.

Based on the clinical examination and clinical presentation, the final diagnosis was made as vitiligo. The vitiligo in this patient was an unclassified type since the patient presented the lesion only in the vermilion border of the lower lip involving the labial mucosa without any other Iesion in other areas of the body. The patient was referred to the dermatologist for further treatment.
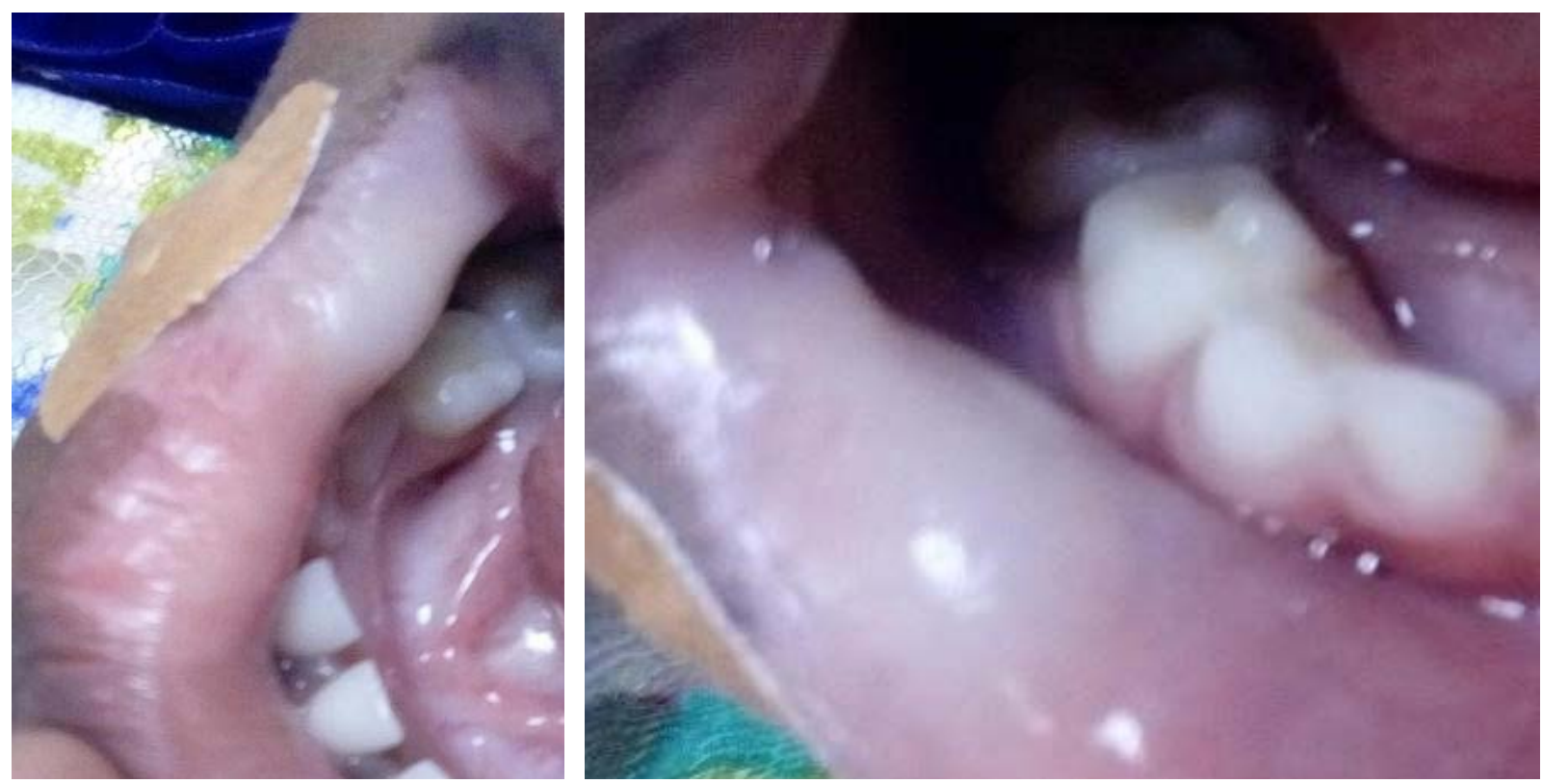

Figure 1. Lesion on the lower vermilion border involving the labial mucosa.

\section{DISCUSSION}

Vitiligo is the most frequently occurring depigmentation disorder, affecting approximately $0.5-1 \%$ of individuals. There is no gender prevalence. Vitiligo is an asymptomatic disease. However, associated symptoms have been demonstrated in some cases, including pruritus and burning sensation of the skin. The symptoms can also be due to psychological distress (5). Vitiligo affects the skin most commonly, which includes neck, face, and scalp. Mucosal involvement of lips, genitals, gingiva and nipples are reported. In oral tissues, vitiligo is very rare. In a systematic review of vitiligo in childhood, autoimmune thyroid disease was found in $14.3 \%$ of patients with vitiligo and it was most commonly seen in female gender, since they report more than the male. The melanocyte dysfunction and disappearance are due to environmental cause, genetic liability, metabolic deformity, impaired renewal, and altered inflammatory and immune respons (7).

Diagnosis is mainly based on clinical features. The Wood's lamp, a hand held ultraviolet irradiation device emitting UVA can be used in the diagnosis of vitiligo. The Wood's lamp detect the areas of depigmentation that is not visible to the naked eye. The vitiligo lesions emit a bright blue-white fluorescence under the Wood's light. The evaluation of the presence of organ-specific autoantibodies, especially those directed against 
thyroid and adrenal glands could be useful to find out whether the disease is associated with an autoimmune disorder (1,11-12).

The vitiligo is classified into segmental and non-segmental vitiligo, non-segmental vitiligo is divided into generalized, acrofacial, universal, mucosal and mixed vitiligo. In Mucosal vitiligo, oral and genital mucosa are involved. Mucosal vitiligo is included in the non-segmental vitiligo, when there is a skin involvement. If skin lesions are not present, mucosal vitiligo is classified as undetermined or unclassified vitiligo (5-7).

The Vitiligo subcommittee of the European Dermatology Forum has given certain guidelines for the management of the vitiligo. The guidelines of the vitiligo management includes, first-line to fourth-line options. The first line of treatment option includes topical treatment that is topical application of corticosteroids and calcineurin inhibitors. The second line of treatment option includes phototherapy (NB-UVA) and psoralen and UVA [PUVA] and systemic steroid treatment. Third line treatment option includes surgical grafting. The fourth line of treatment includes depigmentation. Afamelanotide, the analog of a-melanocyte-stimulating hormone which is synergistic with NB-UVB has shown promising results in promoting re-pigmentation $(1,6,7,9)$. The vitiligo in the oral mucosal region is more resistant to treatment as there is no melanocyte reservoir in those areas because of no hair follicles. The topical tacrolimus is effective in early vitiligo $(8,13)$.

\section{CONCLUSION}

Even though the vitiligo lesions are rare in oral mucosa, when the initial lesions of vitiligo are seen during dental screening, it is very important that the patients are informed and the treatment is started as early as possible since the early intervention shows promising results in treating the lesions of vitiligo. And the dentist along with the dermatologists should identify the most suitable treatment for the patient depending up on the clinical form and extent of the lesions.

Patient consent: Consent for the publication was obtained from the patient's parents.

\section{REFERENCE}

1. Bergqvist C., Ezzedine K. Vitiligo: A Review. Dermatology. 2020 Mar 10:1-22

2. Mu E.W., Cohen B.E., Orlow S.J. Early-onset childhood vitiligo is associated with a more extensive and progressive course. Journal of the American Academy of Dermatology. 2015 Sep 1; 73 (3): 467-70.

3. Sahera S., Reddy Y.V., Kumar D.S. A Rare Case Report of Vitiligo Vulgaris in Pediatric Patient in Tertiary Care Hospital. IOSR Journal of Dental and Medical Sciences. 2020 Jan 20: 42-47.

4. Iannella G., Greco A., Didona D., Didona B., Granata G., MannoA., Pasquariello B., Magliulo G. Vitiligo: pathogenesis, clinical variants and treatment approaches. Autoimmunity reviews. 2016 Apr 1; 15 (4): 335-43.

5. Nicolaidou E., Mastraftsi S., Tzanetakou V., Rigopoulos D. Childhood vitiligo. American journal of clinical dermatology. 2019 Aug $1: 1-2$.

6. Speeckaert R., van Geel N. Vitiligo: an update on pathophysiology and treatment options. American journal of clinical dermatology. 2017 Dec 1; 18 (6): 733-44.

7. Boniface K., Seneschal J., Picardo M., Taïeb A. Vitiligo: focus on clinical aspects, immunopathogenesis, and therapy. Clinical reviews in allergy \& immunology. 2018 Feb 1; 54 (1): 52-67.

8. Ashok N., Karunakaran A., Singh P., Rodrigues J., Ashok N., Tarakji B., Saleh A., Ibrahim A. Gingival vitiligo: report of a case and review of the literature. Case reports in dentistry. 2014 Jan 1; 2014. 
9. Mu E.W., Cohen B.E., Orlow S.J. Early-onset childhood vitiligo is associated with a more extensive and progressive course. Journal of the American Academy of Dermatology. 2015 Sep 1; 73 (3): 467-70.

10. Nagarajan A., Masthan M.K., Sankar L.S., Narayanasamy A.B., Elumalai R. Oral manifestations of vitiligo. Indian journal of dermatology. 2015 Jan; 60 (1): 103.

11. Fricain M., Weidmann P., Roche Y., Fricain J.C. Labial vitiligo associated with a factice disorder: a case report. Journal of Oral
Medicine and Oral Surgery. 2018 Dec 1; 24 (4): 167-9.

12. Andrade S.A., Baeta I.G., Ribeiro M.M., Pratavieira S., Bagnato V.S., Varotti F.D. Mucosal vitiligo in angles of the mouth: clinical and fluorescence aspects. Revista da Associação Médica Brasileira. 2019 Mar; 65 (3): 330-2.

13. Sheth P.K., Sacchidanand S., Asha G.S. Clinico-epidemiological profile of childhood vitiligo. Indian Journal of Paediatric Dermatology. 2015 Jan 1;16 (1): 23. 